\title{
Announcement
}

\section{The Charles R. Ream, MD, Award for Excellence-2002}

In nominating articles for the third annual Charles R. Ream, MD, Award for Excellence, the members of the editorial board of Current Therapeutic Research ${ }^{\circledR}$ recommended a number of worthy studies. However, one article clearly stands out and warrants recognition.

"Complete Results of the First Randomized, Placebo-Controlled Study of Bosentan, a Dual Endothelin Receptor Antagonist, in Pulmonary Arterial Hypertension," by Badesch et $\mathrm{al}^{1}{ }^{1}$ reflects the distinction with which the late Dr. Ream served the journal as Editor-in-Chief for many years. The study, led by a team of American and French investigators working with a Swiss pharmaceutical firm, incorporated some novel design features to study bosentan for the treatment of a rare but life-threatening disease, pulmonary arterial hypertension $(\mathrm{PAH})$. The multinational background of this study underscores the fact that Current Therapeutic Research ${ }^{\circledR}$ is truly an international journal.

Yet, as the authors state, the results had been published previously in a brief report. ${ }^{2}$ Why, then, did we choose to publish this paper and, even more surprising, why was it chosen as an award winner? One reason is that this article presents an enormous amount of previously unpublished data, including a list of each patient's response to therapy, some later data (gathered at 20 and 28 weeks), and an expanded discussion of the importance of these data in the treatment of PAH.

In addition, the study design incorporated an unusual feature: all patients had to remain on medication until the last patient finished 12 weeks of study. Thus, the duration of double-blind treatment ranged from 83 to 202 days, providing data on effectiveness, tolerability, and adverse effects-which are particularly helpful when considering drug therapy for a disease that may require extended treatment. The investigators carried out a short period of dose adjustment by initiating therapy with bosentan $62.5 \mathrm{mg}$ and increasing the dose to $125 \mathrm{mg}$, the intended therapeutic dose. (Previous studies suggest that higher doses may increase the risk of hepatic transaminase elevations. ${ }^{3,4}$ ) The investigators borrowed the main outcome criterion, change in 6-minute walking distance, from research in chronic heart failure ${ }^{5}$ having applied the walking test to previous studies in primary pulmonary hypertension (PPH) ${ }^{6,7}$ Simultaneously, other scientists investigated the walking test to establish its clinical correlates and prognostic significance in $\mathrm{PPH}^{8}{ }^{8}$

What about the magnitude of the treatment effects seen in this study? The $\sim 19 \%$ increase in 6-minute walking distance observed after 12 weeks of bosentan therapy is impressive. Even carrying forward the last observed value for placebo-group members for whom 12-week data were not available (instead 
of being assigned a value of 0 , as indicated by the protocol), a significant difference was still found between treatment arms $(P=0.04, t$ test $){ }^{1}$ The figure illustrating change in 6-minute walking distance is a classic for the placebo response, showing a small, early beneficial effect in the placebo group, followed by a waning of effect and then a steady decline while the bosentan group's mean values increased slowly.

Bosentan tablets are now available on the market for patients with PAH, making Phase IV data collection on effectiveness, tolerability, and adverse effects of the drug possible. As with all new medications, we hope that bosentan will continue to demonstrate a benefit to patients over the long term.

A great deal can be learned about pulmonary hypertension and its treatment from this paper, despite the previous publication of some of the early data. Reviewing the criteria for publication of papers in this journal, as expressed in the Statement of Purpose (clinical relevance, technical accuracy, methodologic rigor, clarity, and objectivity), which exemplify some of the tenets of Dr. Ream's philosophy of science, it becomes clear why this article was chosen for publication and why it was selected for the Ream Award.

As part of the Award, the authors will receive a crystal globe, signifying the international nature of the journal. They will also receive a certificate and our sincere thanks for their strong contribution to the journal.

Michael Weintraub, MD Editor-in-Chief

\section{REFERENCES}

1. Badesch DB, Bodin F, Channick RN, et al. Complete results of the first randomized, placebo-controlled study of bosentan, a dual endothelin receptor antagonist, in pulmonary arterial hypertension. Curr Ther Res Clin Exp. 2002;63:227-246.

2. Channick RN, Simonneau G, Sitbon O, et al. Effects of the dual endothelin-receptor antagonist bosentan in patients with pulmonary hypertension: A randomised placebocontrolled study. Lancet. 2001;358:1119-1123.

3. Mylona P, Cleland JG. Update of REACH-1 and MERIT-HF clinical trials in heart failure. Cardio.net Editorial Team. Eur J Heart Fail. 1999;1:197-200.

4. Krum H, Charlon V, Widmann T, Packer M. Long-term, open-label experience with an endothelin receptor antagonist, bosentan, in patients with severe chronic heart failure. Circulation. 1999;100:I646. Abstract.

5. Guyatt GH, Sullivan MJ, Thompson PJ, et al. The 6-minute walk: A new measure of exercise capacity in patients with chronic heart failure. Can Med Assoc J. 1985;132: 919-923.

6. Barst RJ, Rubin LJ, Long WA, et al. A comparison of continuous intravenous epoprostenol (prostacyclin) with conventional therapy for primary pulmonary hypertension. The Primary Pulmonary Hypertension Study Group. N Engl J Med. 1996;334:296-302. 
7. Badesch DB, Tapson VF, McGoon MD, et al. Continuous intravenous epoprostenol for pulmonary hypertension due to the scleroderma spectrum of disease. A randomized, controlled trial. Ann Intern Med. 2000;132:425-434.

8. Miyamoto S, Nagaya N, Satoh T, et al. Clinical correlates and prognostic significance of six-minute walk test in patients with primary pulmonary hypertension. Comparison with cardiopulmonary exercise testing. Am J Respir Crit Care Med. 2000;161:487-492. 